\title{
Condições socioeconômicas e estado nutricional de famílias rurais
}

\author{
Dayane de Castro Morais, Luiza Veloso Dutra, Sylvia do Carmo Castro Franceschini, Juliana Farias \\ de Novaes, Silvia Eloiza Priore
}

\section{Resumo}

Aumento da obesidade e manutenção de doenças carenciais, como baixa estatura, caracterizam transição nutricional. A presença de baixa estatura, inclusive em adultos, é indicador de déficit nutricional cumulativo, também conhecido como desnutrição pregressa. Objetivou-se relacionar estado nutricional de famílias rurais brasileiras e condições socioeconômicas. Trata-se de estudo transversal com famílias rurais do município de São Miguel do Anta, Minas Gerais. Para cálculo amostral utilizou-se programa STATCALC do EPI-INFO, versão 6.04, e prevalência de insegurança alimentar em Minas Gerais, segundo Pesquisa Nacional de Amostras de Domicílios (2009), sendo acrescido de $10 \%$ para possíveis perdas e $20 \%$ para controle de fatores de confusão, resultando em amostra de 79 domicílios. As famílias da amostra foram sorteadas a partir do cadastro de agricultores familiares da Empresa de Assistência Técnica e Extensão Rural - EMATER do município, respeitando a proporcionalidade de famílias por comunidade rural. Este trabalho foi aprovado pelo comitê de ética da Universidade Federal de Viçosa, sob o número de registro 241.906/2013, e todos os participantes assinaram o termo de consentimento livre esclarecido. Aferiu-se peso e estatura de todos os integrantes das famílias, e calculou-se índices de massa corporal (IMC) e estatura/idade, inclusive em adultos (considerando idade máxima obtida pelas curvas de crescimento), utilizando pontos de corte da Organização Mundial da Saúde, específicos para cada faixa etária. Avaliou-se renda, número de moradores, idade e sexo. Para verificar situação de pobreza, considerou-se renda per capita inferior a $1 / 2$ salário mínimo, vigente no período da coleta de dados (R \$311,00). Realizou-se testes de qui-quadrado de Pearson e correlação de Spearman. Avaliou-se 79 famílias (272 indivíduos). Em relação às famílias, 93,7\% eram chefiadas por homens e $54,4 \%$ estavam em situação de pobreza. Considerando estado nutricional, $25,3 \%$ e $31,6 \%$ das famílias apresentavam obesidade e baixa estatura, respectivamente, em pelo menos um integrante. Presença de pobreza não associou-se à baixa estatura e obesidade na família. Renda per capita correlacionou-se ao número de integrantes com baixa estatura na família $(r=-0,248 ; p=0,027)$, mas não aos com obesidade. Ao considerar baixa estatura apenas em crianças e adolescentes, observouse 5 indivíduos com essa distrofia, estando em 3,8\% dos domicílios. Ao incluir adultos nessa análise, verificou-se 34 indivíduos com baixa estatura (31,6\% dos domicílios). A renda per capita correlacionou-se ao número de idosos na família $(\mathrm{r}=0,587 ; \mathrm{p}<0,001)$ e inversamente com número de crianças $(r=-0,475 ; \mathrm{p}=0,001)$ e adolescentes $(\mathrm{r}=-0,448 ; \mathrm{p}<0,001)$. Esses resultados indicam a importância de avaliar baixa estatura também em adultos, como indicador de déficit nutricional cumulativo, e considerar baixa renda per capita como fator de risco para essa deficiência.

Descritores: Baixa estatura; Obesidade; Pobreza. 